\title{
Optimum Composition for High Strength Aluminium Flux Using the Gauss-Jordan Row Operation Model
}

\author{
Joseph Achebo, Monday Omoregie \\ Department of Production Engineering, University of Benin, Benin City, Edo State, Nigeria
}

Email address:

josephachebo@yahoo.co.uk (J. Achebo), mjomoregie@yahoo.com (M. Omoregie)

To cite this article:

Joseph Achebo, Monday Omoregie. Optimum Composition for High Strength Aluminium Flux Using the Gauss-Jordan Row Operation Model. International Journal of Materials Science and Applications. Vol. 4, No. 3, 2015, pp. 198-202. doi: 10.11648/j.ijmsa.20150403.17

\begin{abstract}
Globally, aluminium and its alloys are generally regarded as materials that are difficult to weld. Research is ongoing with a view to finding newer and better ways to repair or weld these alloys. Consequently various mathematical models are currently being adapted to formulate new compositions for aluminium welding fluxes. In this study, a new flux was developed for the welding of high strength aluminium alloy using the Gauss Jordan Row Operation model. By applying this model, an optimum composition of $39 \% \mathrm{NaCl}, 20.5 \% \mathrm{CaCl}_{2}, 20.5 \% \mathrm{KCl}, 6 \% \mathrm{CaF}_{2}$, and $14 \% 3 \mathrm{NaFAlF}_{3}$, was obtained. The weldment which resulted from the application of this optimum flux was subjected to certain mechanical tests, such as the tensile test, hardness test, and micro-structural analysis. The ultimate tensile strength of the weld was found to be $428 \mathrm{MPa}, 0.2 \%$ proof stress of $305 \mathrm{MPa}$, and a Brinell hardness number of 94. These values compare well with published values in literature. Also from the micro-structural analysis, the weld is confirmed to be of good quality. A systematic (step by step) approach has been applied in this research work and found to be very rewarding.
\end{abstract}

Keywords: Aluminium, Flux, Gauss-Jordan Row Operation Model, Mechanical Properties

\section{Introduction}

Aluminium alloys are popular materials used to fabricate a wide variety of appliances, components, and parts. The alloys are indigenously sourced in commercial quantities and widely available. However, these alloys are considered difficult to weld leading to ongoing research on finding newer and more efficient ways to weld them.

In his work on welding of aluminium, Achebo [1] wrote that Aluminium is ubiquitous in application and is of great relevance in nearly all fields of technological research and development and that it was invariably, the same with its welding fluxes. Fluxes are invaluable because they facilitate the removal of the tenacious Aluminium Hydrated Oxide layer $(\mathrm{AlOH})$ which is always found on Aluminium surfaces which have been exposed to atmospheric oxygen. The presence of $\mathrm{AlOH}$ makes the welding of aluminium alloys difficult. Therefore, it is practically not possible to weld aluminium without the use of a flux.

In Nigeria, aluminium welding is not generally embarked upon because available fluxes are imported and are very expensive. Technicians therefore usually prefer to replace damaged aluminium alloy parts rather than attempt to repair them. However, and as observed by Achebo and Ibhadode [2] the outcome of Dr Achebo's pioneering work, introduced the first aluminium welding flux made wholly from indigenously sourced local materials. This development is expected to eventually make the routine welding of aluminium and its alloys a more viable option to technicians.Achebo and Ibhadode[2] observed that researchers in more developed countries have made significant efforts over the years in the development of efficient fluxes used for welding metals in general. Jackson [3] developed enhanced welding fluxes and studied their slag formation. Sham and Liu [4] designed a methodology for developing SMAW consumable electrode flux coatings for high-nickel alloys. The flux formulation design began with an equal distribution of three primary ingredients: cryolite, rutile, and calcium carbonate. It was found that the flux enhanced extrudability, weld cleanliness, slag detachability, alloying recovery, welding characteristics, and arc quality.

Manfredi et al [5] characterized the physical and chemical properties of aluminium dross. Nikitina [6] developed compositions of electrode coating for welding aluminium by applying the expert evaluation method. Achebo and Ibhadode[7] developed an optimum welding flux composition 
used for welding aluminium alloys applying the bend strength testing technique.

Each composition of electrode coatings (fluxes) has a peculiar effect on the mechanical properties of the eventual weld. Different welding processes were used for welding using these coated electrodes.

This study has taken the development of welding fluxes a step forward with emphasis on local contents. It is expected that this would enable welds of high strength to be effected. Singh et al. [8] were of the opinion that performance of a welding flux is decided by the physical and chemical properties of its constituents. The flux selected according to the authors should show a good welding behavior and the required weld bead geometry. They also said that the mechanical properties of a joint are not only decided by its composition but these also depends on bead geometry, dimensions and physico-chemical properties of fluxes

To this end, this research is aimed at producing a flux composition geared towards the attainment of optimum strength qualities in the welding of aluminium by applying the Gauss-Jordan row operation model.

\section{Materials and Methods}

\subsection{Materials}

The materials that were used for the production of high strength aluminium flux are Fluorspar, Cryolite, Calcium carbonate, Calcium Chloride, Hydrochloric Acid, Potassium Chloride, Sodium Chloride. These raw materials were sourced locally but Calcium Chloride and Potassium Chloride were obtained by the precipitation processes in the laboratory when Calcium Carbonate and Potassium Ash were made to react with Hydrochloric acid respectively.

A Tungsten Inert Gas (TIG) welding machine with a voltage of $22 \mathrm{~V}$, a current of $360 \mathrm{~A}$, gas flow rate of $20 \mathrm{l} / \mathrm{min}$ and electrode angle of 45 degrees was used to make the aluminium weld deposits and $100 \%$ Argon gas was used as the shielding gas.

\subsection{Methods}

The following method was adopted in this study

1. The Gauss-Jordan row operation model was used to develop a 5 x 5 matrix design

2. The matrix design contains an " 0 " which stands for the low level of the composition range of the flux constituent elements (see Table 2) and "1" stands for high level.

3. Table 1 contains the composition ranges of each element that make up the flux material. The smaller number indicates the low level and the higher number indicates the high level. These values in Table 1 were substituted into the matrix design in Table 2 to obtain the five flux element combinations, also presented in Table 2.

4. These flux combinations were each used to conduct welding operations by depositing weld metals.

5. The microstructure of each deposited weld metal we reassessed by Experts by using the criteria presented in
Table 3.

6. The responses of the Experts are shown in Table 2.

7. The five flux combinations and the Experts' responses (see Table 2) were optimized using the Gauss-Jordan row operation model.

8. The optimized flux element combination was evaluated to determine its suitability and quality by determining the mechanical properties of the weld metal deposits as listed herein-under and comparing them with those obtained from other literature.

\section{Mechanical Tests}

The following mechanical tests were carried out:

1. Tensile tests were performed on the weldment specimens using the Monsato Extensometer and the yield strength, ultimate tensile strength, fracture strength, and percent elongation were obtained.

2. The Avery Brinell hardness tester was used to determine the hardness number of well polished weldment samples with $0.5 \mu \mathrm{m}$ emery cloth and etched with $0.2 \% \mathrm{SiC}$ solution. The Econet II polisher was utilized in the polishing operation.

3. A ARL1640 model spectrometer made in Switzerland was used to determine the chemical composition of the polished weldment.

4. The polished weldment was further put under an Avery microscope where the weldment microstructure was displayed on a computer monitor and the weldment microstructural view was printed out.

\section{Presentation of Results}

Table 1 shows the composition ranges of elements used for the production of aluminium welding flux.

Table 1. Composition Ranges of Flux Elements

\begin{tabular}{ccc}
\hline Element & & \% by wt \\
\hline $\mathrm{NaCl}$ & $x_{1}$ & $35-45$ \\
$\mathrm{CaCl}$ & $x_{2}$ & $20-35$ \\
$\mathrm{KCl}$ & $x_{3}$ & $15-30$ \\
$\mathrm{CaF}_{2}$ & $x_{4}$ & $2-7$ \\
$3 \mathrm{NaFAlF}_{3}$ & $x_{5}$ & $3-8$ \\
\hline
\end{tabular}

Five chemical compositions were obtained from the range of elements in Table 1 and were arranged in a matrix form in Table 2 .

Table 2. Composition Matrix

\begin{tabular}{cccccccccccc}
\hline $\mathbf{x}_{\mathbf{1}}$ & $\mathbf{x}_{\mathbf{2}}$ & $\mathbf{x}_{\mathbf{3}}$ & $\mathbf{x}_{\mathbf{4}}$ & $\mathbf{x}_{\mathbf{5}}$ & $\mathbf{M}$ & $\mathbf{a}$ & $\mathbf{t}$ & $\mathbf{r}$ & $\mathbf{i}$ & $\mathbf{x}$ & Response \\
\hline 40 & 20 & 30 & 4 & 6 & 1 & 0 & 0 & 0 & 0 & 5 \\
45 & 25 & 20 & 6 & 4 & 0 & 1 & 0 & 0 & 0 & 4 \\
35 & 30 & 25 & 3 & 7 & 0 & 0 & 1 & 0 & 0 & 5 \\
40 & 35 & 15 & 7 & 3 & 0 & 0 & 0 & 1 & 0 & 4 \\
40 & 25 & 25 & 2 & 8 & 0 & 0 & 0 & 0 & 1 & 4 \\
\hline
\end{tabular}

In Table 2, the microstructure of each weld made from each chemical composition were classified by experts as follows: 
Table 3. Microstructure Classification

\begin{tabular}{ll}
\hline MicrostructureClassification & Ranking \\
\hline Very Good & 5 \\
Good & 4 \\
Undecided & 3 \\
Bad & 2 \\
Very Bad & 1 \\
\hline
\end{tabular}

Applying the Gauss-Jordan row operation model to Table 2, the following are obtained.

Divide row 1 by 40, row 2 by 45 , row 3 by 35, row 4 by 40 and row 5 by 40 . From the calculation above Table 4 was created.

Table 4. First row iteration

\begin{tabular}{cccccc}
\hline $\mathbf{x}_{\mathbf{1}}$ & $\mathbf{x}_{\mathbf{2}}$ & $\mathbf{x}_{\mathbf{3}}$ & $\mathbf{x}_{\mathbf{4}}$ & $\mathbf{x}_{\mathbf{5}}$ & Response \\
\hline 1 & $\frac{1}{2}$ & $\frac{3}{4}$ & $\frac{1}{10}$ & $\frac{3}{20}$ & $\frac{1}{8}$ \\
1 & $\frac{5}{9}$ & $\frac{4}{9}$ & $\frac{2}{15}$ & $\frac{4}{45}$ & $\frac{4}{45}$ \\
1 & $\frac{6}{7}$ & $\overline{7}$ & $\frac{3}{35}$ & $\frac{1}{5}$ & $\frac{1}{7}$ \\
1 & $\overline{7}$ & $\frac{3}{8}$ & $\frac{7}{40}$ & $\frac{3}{40}$ & $\frac{1}{10}$ \\
1 & $\overline{5}$ & $\frac{5}{8}$ & $\frac{1}{20}$ & $\frac{1}{5}$ & $\frac{1}{10}$ \\
\hline
\end{tabular}

From Table 4, subtract 1 from row 2, row 3, row 4 and row 5 and Table 5 is created.

Table 5. Second row iteration

\begin{tabular}{cccccc}
\hline $\mathbf{x}_{1}$ & $\mathbf{x}_{\mathbf{2}}$ & $\mathbf{x}_{\mathbf{3}}$ & $\mathbf{x}_{\mathbf{4}}$ & $\mathbf{x}_{\mathbf{5}}$ & Response \\
\hline 1 & $\frac{1}{2}$ & $\frac{3}{4}$ & $\frac{1}{10}$ & $\frac{3}{20}$ & $\frac{1}{8}$ \\
0 & $\frac{-4}{9}$ & $\frac{-5}{9}$ & $\frac{-13}{15}$ & $\frac{-41}{45}$ & $\frac{-41}{45}$ \\
0 & $\frac{-1}{7}$ & $\frac{-2}{7}$ & $\frac{-32}{35}$ & $\frac{-4}{5}$ & $\frac{-6}{7}$ \\
0 & $\frac{-1}{8}$ & $\frac{-5}{8}$ & $\frac{-33}{40}$ & $\frac{-37}{40}$ & $\frac{-9}{10}$ \\
0 & $\frac{-3}{8}$ & $\frac{-3}{8}$ & $\frac{-19}{20}$ & $\frac{-4}{5}$ & $\frac{-9}{10}$ \\
\hline
\end{tabular}

From Table 5 multiply row 2 by $-9 / 4$, row 3 by -7 , row 4 by -8 and row 5 by $-8 / 3$ and Table 6 was created.

Table 6. Third row iteration

\begin{tabular}{cccccc}
\hline $\mathbf{x}_{\mathbf{1}}$ & $\mathbf{x}_{\mathbf{2}}$ & $\mathbf{x}_{\mathbf{3}}$ & $\mathbf{x}_{\mathbf{4}}$ & $\mathbf{x}_{\mathbf{5}}$ & Response \\
\hline 1 & $\frac{1}{2}$ & $\frac{3}{4}$ & $\frac{1}{10}$ & $\frac{3}{20}$ & $\frac{1}{8}$ \\
0 & 1 & $\frac{5}{4}$ & $\frac{39}{20}$ & $\frac{41}{20}$ & $\frac{41}{20}$ \\
0 & 1 & 2 & $\frac{32}{5}$ & $\frac{28}{5}$ & 6 \\
0 & 1 & 5 & $\frac{33}{5}$ & $\frac{37}{5}$ & $\frac{36}{5}$ \\
0 & 1 & 1 & $\frac{38}{15}$ & $\frac{32}{15}$ & $\frac{36}{15}$ \\
\hline
\end{tabular}

From Table 6 subtract row 4 from row 3 , row 5 from row 4 and row 2 from row 5 and Table 7 was created.

Table 7. Fourth row iteration

\begin{tabular}{cccccc}
\hline $\mathbf{x}_{\mathbf{1}}$ & $\mathbf{x}_{\mathbf{2}}$ & $\mathbf{x}_{\mathbf{3}}$ & $\mathbf{x}_{\mathbf{4}}$ & $\mathbf{x}_{\mathbf{5}}$ & Response \\
\hline 1 & $\frac{1}{2}$ & $\frac{3}{4}$ & $\frac{1}{10}$ & $\frac{3}{20}$ & $\frac{1}{8}$ \\
0 & 1 & $\frac{5}{4}$ & $\frac{39}{20}$ & $\frac{41}{20}$ & $\frac{41}{20}$ \\
0 & 0 & -3 & $\frac{-1}{5}$ & $\frac{-9}{5}$ & -6 \\
0 & 0 & 4 & $\frac{61}{15}$ & $\frac{79}{15}$ & $\frac{24}{5}$ \\
0 & 0 & $\frac{-1}{4}$ & $\frac{7}{12}$ & $\frac{1}{12}$ & $\frac{21}{60}$ \\
\hline
\end{tabular}

From Table 7 multiply row 3 by $-1 / 3$, row 4 by $1 / 4$ and row 5 by -4 and Table 8 was created.

Table 8. Fifth row iteration

\begin{tabular}{cccccc}
\hline $\mathbf{x}_{\mathbf{1}}$ & $\mathbf{x}_{\mathbf{2}}$ & $\mathbf{x}_{\mathbf{3}}$ & $\mathbf{x}_{\mathbf{4}}$ & $\mathbf{x}_{\mathbf{5}}$ & Response \\
\hline 1 & $\frac{1}{2}$ & $\frac{3}{4}$ & $\frac{1}{10}$ & $\frac{3}{20}$ & $\frac{1}{8}$ \\
0 & 1 & $\frac{5}{4}$ & $\frac{39}{20}$ & $\frac{41}{20}$ & $\frac{41}{20}$ \\
0 & 0 & 1 & $\frac{1}{15}$ & $\frac{3}{5}$ & 2 \\
0 & 0 & 1 & $\frac{61}{60}$ & $\frac{79}{60}$ & $\frac{24}{20}$ \\
0 & 0 & 1 & $\frac{-7}{3}$ & $\frac{-1}{3}$ & $\frac{-7}{5}$ \\
\hline
\end{tabular}

From Table 8 subtract row 3 from row 4 and also from row 5 and Table 9 was created.

Table 9. Sixth row iteration

\begin{tabular}{cccccc}
\hline $\mathbf{x}_{\mathbf{1}}$ & $\mathbf{x}_{\mathbf{2}}$ & $\mathbf{x}_{\mathbf{3}}$ & $\mathbf{x}_{\mathbf{4}}$ & $\mathbf{x}_{\mathbf{5}}$ & Response \\
\hline 1 & $\frac{1}{2}$ & $\frac{3}{4}$ & $\frac{1}{10}$ & $\frac{3}{20}$ & $\frac{1}{8}$ \\
0 & 1 & $\frac{5}{4}$ & $\frac{39}{20}$ & $\frac{41}{20}$ & $\frac{41}{20}$ \\
0 & 0 & 1 & $\frac{1}{15}$ & $\frac{3}{5}$ & 2 \\
0 & 0 & 1 & $\frac{57}{60}$ & $\frac{43}{60}$ & $\frac{-4}{5}$ \\
0 & 0 & 1 & $\frac{-12}{5}$ & $\frac{-14}{15}$ & $\frac{-17}{5}$ \\
\hline
\end{tabular}

From Table 9 multiply row 4 by $60 / 57$ and row 5 by $-5 / 12$ and Table 10 was created.

Table 10. Seventh row iteration

\begin{tabular}{cccccc}
\hline $\mathbf{x}_{\mathbf{1}}$ & $\mathbf{x}_{\mathbf{2}}$ & $\mathbf{x}_{\mathbf{3}}$ & $\mathbf{x}_{\mathbf{4}}$ & $\mathbf{x}_{\mathbf{5}}$ & Response \\
\hline 1 & $\frac{1}{2}$ & $\frac{3}{4}$ & $\frac{1}{10}$ & $\frac{3}{20}$ & $\frac{1}{8}$ \\
0 & 1 & $\frac{5}{4}$ & $\frac{39}{20}$ & $\frac{41}{20}$ & $\frac{41}{20}$ \\
0 & 0 & 1 & $\frac{1}{15}$ & $\frac{3}{5}$ & 2 \\
0 & 0 & 0 & 1 & $\frac{43}{57}$ & $\frac{-48}{57}$ \\
0 & 0 & 0 & 1 & $\frac{7}{18}$ & $\frac{17}{12}$ \\
\hline
\end{tabular}


From Table 10 subtract row 4 from row 5 and Table 11 was created.

Table 11. Eighth row iteration

\begin{tabular}{cccccc}
\hline $\mathbf{x}_{1}$ & $\mathbf{x}_{\mathbf{2}}$ & $\mathbf{x}_{\mathbf{3}}$ & $\mathbf{x}_{\mathbf{4}}$ & $\mathbf{x}_{\mathbf{5}}$ & Response \\
\hline 1 & $\frac{1}{2}$ & $\frac{3}{4}$ & $\frac{1}{10}$ & $\frac{3}{20}$ & $\frac{1}{8}$ \\
0 & 1 & $\frac{5}{4}$ & $\frac{39}{20}$ & $\frac{41}{20}$ & $\frac{41}{20}$ \\
0 & 0 & 1 & $\frac{1}{15}$ & $\frac{3}{5}$ & 2 \\
0 & 0 & 0 & 1 & $\frac{43}{57}$ & $\frac{-48}{57}$ \\
0 & 0 & 0 & 1 & $\frac{-125}{342}$ & $\frac{515}{228}$ \\
\hline
\end{tabular}

From Table 11 multiply row 5 by $-342 / 125$ and Table 12 was created.

Table 12. Nineth row iteration

\begin{tabular}{cccccc}
\hline $\mathbf{x}_{\mathbf{1}}$ & $\mathbf{x}_{\mathbf{2}}$ & $\mathbf{x}_{\mathbf{3}}$ & $\mathbf{x}_{\mathbf{4}}$ & $\mathbf{x}_{\mathbf{5}}$ & Response \\
\hline 1 & $\frac{1}{2}$ & $\frac{3}{4}$ & $\frac{1}{10}$ & $\frac{3}{20}$ & $\frac{1}{8}$ \\
0 & 1 & $\frac{5}{4}$ & $\frac{39}{20}$ & $\frac{41}{20}$ & $\frac{41}{20}$ \\
0 & 0 & 1 & $\frac{1}{15}$ & $\frac{3}{5}$ & 2 \\
0 & 0 & 0 & 1 & $\frac{43}{57}$ & $\frac{-48}{57}$ \\
0 & 0 & 0 & 0 & 1 & -309 \\
\hline
\end{tabular}

Expressing the matrix in Table 12 into simultaneous equations as shown in Table 13

Table 13. Simultaneous equations

\begin{tabular}{|c|c|c|c|c|c|}
\hline $\mathrm{X}_{1}$ & $\begin{array}{c}+\frac{1}{2} x_{2} \\
x_{2}\end{array}$ & $\begin{array}{c}+\frac{3}{4} x_{3} \\
+\frac{5}{4} x_{3} \\
x_{3}\end{array}$ & $\begin{array}{c}+\frac{1}{10} x_{4} \\
+\frac{39}{20} x_{4} \\
+\frac{1}{15} x_{4} \\
\mathrm{x}_{4}\end{array}$ & $\begin{array}{c}+\frac{3}{20} x_{5} \\
+\frac{41}{20} x_{5} \\
+\frac{3}{5} x_{5} \\
+\frac{43}{57} x_{5} \\
x_{5}\end{array}$ & $\begin{array}{c}=\frac{1}{8} \\
=\frac{41}{20} \\
=2 \\
=\frac{-48}{57} \\
=\frac{-309}{50}\end{array}$ \\
\hline
\end{tabular}

From the above expression, we obtain: $\mathrm{x}_{1}=-3.64, \mathrm{x}_{2}=$ $0.46, \mathrm{x}_{3}=5.45, \mathrm{x}_{4}=3.82$ and $\mathrm{x}_{5}=-6.18$

The negative numbers are subtracted from the upper range values and the positive numbers are added to the lower range values as shown in Table 1

We therefore have $\mathrm{x}_{1}=39.36 \%, \mathrm{x}_{2}=20.46 \%, \mathrm{x}_{3}=20.45 \%$, $\mathrm{x}_{4}=5.82 \%$ and $\mathrm{x}_{5}=1.82 \%$

Considering $\mathrm{x}_{5}$, when -6.18 was added to 8 , we arrived at 1.82 which was outside the range of $3-8 \%$ by weight. It therefore means that this range may not have been adequately selected. Therefore it would have to be expanded by adding 6.18 to the upper limit, which gave $14.18 \%$. By reducing the range, the entire composition would not be $100 \%$ by weight. Therefore, the only option is to expand. Utigard et al [9] and
Achebo [1] were of the opinion that fluoride salts can be up to $20 \%$ by weight. Therefore, this claim further confirms that $14 \%$ $3 \mathrm{NaFAlF}_{3}$ selected, falls within the acceptable limits used by other researchers. The new flux composition using the Guass-Jordan row operation model is:

$\mathrm{x}_{1}=39 \%, \mathrm{x}_{2}=20.5 \%, \mathrm{x}_{3}=20.5 \%, \mathrm{x}_{4}=6 \%$ and $\mathrm{x}_{5}=14 \%$.

This translates to:

$$
\begin{gathered}
39 \% \mathrm{NaCl}, 20.5 \% \mathrm{CaCl}_{2}, 20.5 \% \mathrm{KCl}, 6 \% \mathrm{CaF}_{2}, 14 \% \\
3 \mathrm{NaFAlF}_{3}
\end{gathered}
$$

\section{Discussion of Results}

To test for the superiority of the quality of the weld made by the flux from the optimum composition, the weld specimens were subjected to tests to determine their mechanical properties. These tests include the tensile test, hardness test, and micro structural analysis.

From the tensile tests conducted, the ultimate tensile strength of the weld made by the optimum flux formulation is $428 \mathrm{MPa}$ whereas; the $0.2 \%$ proof stress is $305 \mathrm{MPa}$. The percent elongation is $12 \%$. These values were compared with values obtained from other literature such as reported by Padmanabham et al. [10] in their studies on the tensile properties of welded joints made by various welding processes as presented in Table 14.

Table 14. Comparison of Tensile Properties made from other welding processes

\begin{tabular}{llll}
\hline Process & Material/Filler & Test Condition & Thickness \\
\hline Laser & $2195 /$ & AlSi12 & As welded \\
Welding & $3 \mathrm{~mm}$ & in T8 & \\
GTAW & $2094-\mathrm{T} 8$ & 2319 & As-welded \\
VPPAW & $2094-\mathrm{T} 8$ & 2319 & As-welded \\
GMAW & $2094-\mathrm{T} 8$ & 2319 & As-welded \\
EBW & $2094-\mathrm{T} 8$ & - & As-welded \\
Pulsed- & Experimental & & As-welded \\
GMAW & & & \\
Gas welding - & /10mm & - & As-welded \\
(Local flux) & & & \\
Process & $0.2 \%$ Proof & $\mathrm{UTSMPa}$ & $-50 \mathrm{~mm})$ \\
Laser & Stress, MPa & 325 & 1.1 \\
Welding & 285 & & \\
GTAW & - & 352 & - \\
VPPAW & 269 & 372 & - \\
GMAW & - & 283 & - \\
EBW & - & 434 & 1.5 \\
Pulsed- & 221 & 298 & \\
GMAW & & 310 & \\
Gas & 203 & & \\
welding (Local flux $)(2)$ & &
\end{tabular}

Source: Padmanabham et al. [10]

Achebo and Ibhadode [2] determined the tensile properties of the weld made from locally available raw materials. The ultimate tensile strength of the weld is $310 \mathrm{MPa}, 0.2 \%$ Proof stress is $203 \mathrm{MPa}$, whereas, the percentage elongation is $8 \%$. From the tensile strength obtained, it is clear that the optimum flux composition produced the weld with superior mechanical 
properties when compared with the values found in other literature.

In Table 14, the weld made from Electron Beam Welding (EBW) process has ultimate tensile strength of 434MPa higher than the one made from applying the optimum welding flux composition. This variation in the value of the tensile properties could be due to the type of process parameters used for welding, amount of alloying elements present in the weld, the skill of the welder and the welding process. The weld made by using the optimum welding flux composition was subjected to the Brinell hardness test and the Brinell hardness number (BHN) was determined to be 94 .

Achebo [1] determined the BHN for the weld made from using the locally produced flux to be 100 . The lower value of $94 \mathrm{BHN}$ indicates that the optimum weld is not as hard as the weld made by Achebo and Ibhadode[2]. This would further show the reason the percent elongation of $12 \%$ of the optimum weld is higher than the $8 \%$ made by the weld produced by Achebo and Ibhadode [2]. The microstructure analysis of the welds made by using the optimum flux composition was carried out. It is found from Fig 1, that the microstructure is influenced by a heterogeneously distributed metallic grains which contain both cementite and paerlite grains.

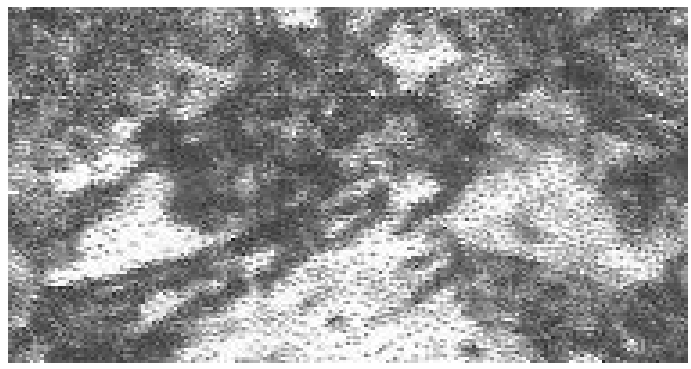

Fig. 1. Microstructure of optimum Weld

\section{Conclusion}

The Gauss-Jordan row operation model has been successfully applied to develop aluminium welding flux for high strength aluminium alloys. The tensile properties of the optimally produced flux are impressive and surpass those found in literature. However, its Brinell hardness number is lower than some values reported in literature. This hardness value further confirms the ductile nature of the weld. The newly formulated welding composition show a novel approach in the development of a suitable welding flux and to the best knowledge of the authors, this appears to be the first that the Gauss-Jordan row operation model has been applied in optimizing and developing a welding flux composition.

\section{References}

[1] J.I. Achebo, "A Multiphysics Analysis of Aluminum Welding Flux Composition Optimization Methods", in Advances in Computer Science and Engineering, Chapter 11, Edited by Matthias Schmidt, INTECH Open Access Publication, Rijeka, Croatia, 2011, pp 215-236.

[2] J. I. Achebo, and A. O. A. Ibhadode, Development of a New Flux for Aluminium Gas Welding, Materials and Product Technologies, Edited by Z. Y. Shen; M. N. James; W. D. Li, and Y. X. Zhao., Trans Tech Publications Ltd, Switzerland, Vol. 44 46 of Advanced Materials Research, 2008,pp677- 684

[3] C.E. Jackson, 'Fluxes and Slags in Welding' Welding Research Council Bulletins 190, 1973,pp25-57.

[4] K. Sham and S. Liu. Flux Coating Development for SMAW Consumable Electrode of High Nickel Alloys. Welding Journal, 8, 2014,pp. 271s - 281s

[5] O. Manfredi, W.Wulh, and I. Bohlinger, Characterizing the Physical and Chemical Properties of Aluminum Dross JOM,1997,pp 48

[6] E. V. Nikitina, Development of the Composition of Electrode Coatings for WeldingAluminum Alloys Using the Expert Evaluation Method', Welding International,18(4), 2004,pp 307-310.

[7] J. I. Achebo, and A. O. AIbhadode, 'Development of Optimum Welding Flux Composition using the Bend Strength Test' Materials and Product Technologies, Edited by A. O. A. Ibhadode. Trans Tech Publications Ltd, Switzerland, Vol. 62 64 of Advanced Materials Research, 2009,pp393-397

[8] B. Singh, Z.A.Khan and A. N.Siddiquee. Review on effect of flux composition on its behavior and bead geometry in submerged arc welding (SAW), Journal of Mechanical Engineering Research, Vol. 5(7), pp.123 -127, October 2013 DOI 10.5897/JMER2013.0284

[9] T. A. Utigard, K. Friesen, R. R.Roy, J. Lim, A. Silny and C. Dupuis, The Properties and Uses of Fluxes in Molten Aluminum Processing' JOM, 1998, pp 38

[10] G. Padmanabham, M. Schaper, S. Pandey, and E. Simmchen,. Tensile and Fracture Behavior of Pulsed Gas Metal Arc Welded $\mathrm{Al}-\mathrm{Cu}-\mathrm{Li}$. Welding Journal, 86, 2007,pp147s - 160s. 